\title{
Kanatlarına Basamak Açmanın Darrieus Düşey Eksenli Rüzgar Türbini Güç Üretimine Etkisi
}

\author{
Sercan ACARER ${ }^{* 1}$ \\ 1İzmir Katip Çelebi Üniversitesi, Mühendislik ve Mimarlık Fakültesi, Makine \\ Mühendisliği Bölümü, 35620, Çiğli, İzmir
}

(Alınıș / Received: 07.09.2016, Kabul / Accepted: 09.01.2017, Online Yayınlanma / Published Online: 02.05.2017)

\begin{abstract}
Anahtar Kelimeler Özet: Bir kanadın firar kenarı tarafına basamak açmanın, o Darrieus, Düșey Eksenli, Rüzgar Türbini, Kline-Fogleman, Basamak, HAD kanadın kaldırma/sürükleme kuvvet oranını arttırabildiği literatürde belirlenmiştir. $\mathrm{Bu}$ tip kanatlara Kline-Fogleman kanatları denmektedir. Düşey eksenli Darrieus rüzgar türbinleri ise kanatların kaldırma kuvvetiyle dönen türbinlerdir. $\mathrm{Bu}$ türbinlerin güç artış potansiyellerinin ortaya çıkarılması literatürde yoğunlukla çalışılan güncel bir bilimsel araştırma konusudur.

$\mathrm{Bu}$ çalışmada Kline-Fogleman kanatlarının Darrieus türbininde, yazarların bilgisi dahilinde, literatürde ilk defa kullanılmasının güç üretimine etkisi, önceden doğrulanmış hesaplamalı akışkanlar mekaniği (HAD) analizleri vasıtasıyla incelenmiştir. Yapılan karşılaștırmalarla, bunun olumlu ve olumsuz etkilerinin olduğu saptanmıştır. İleriki çalışmalarda aktif kontrollü farklı basamak geometrileriyle iyileştirmeler elde edilmesi mümkün gözükmektedir. Bu çalışmanın, konusunda bir referans çalışma olması beklenmektedir.
\end{abstract}

\section{The Effect of Airfoil Backward-Facing Step on Power Production of a Darrieus Vertical-Axis Wind Turbine}

\begin{tabular}{ll}
\hline Keywords & Abstract: Airfoils which have backward facing steps are called \\
Darrieus, & Kline-Fogleman airfoils and those have previously shown to have \\
Vertial Axis, & lift/drag enhancement potentials over conventional airfoils. \\
Wind Turbine, & Darrieus vertical-axis wind turbines rotate by the lift generated on \\
Kline-Fogleman, & its airfoils. The exploration of power enhancement potentials of \\
Step, & such turbines is a current scientific topic in the literature. \\
CFD & In this study, the effects of stepped airfoils in a Darrieus turbine is \\
& studied by validated computational fluid dynamics (CFD) \\
& simulations, to the author's best knowledge, for the first time in \\
& the open literature. The comparisons revealed that this has both \\
& positive and negative effects. Optimized step geometries with \\
& active flow control may eliminate negative aspects and improve \\
& overall performance. This study is expected to be a reference \\
& study on this area.
\end{tabular}

*Sercan ACARER, sercanacarer@gmail.com 


\section{Giriş}

Rüzgâr enerjisini faydalı ișe dönüștüren çeşitli türbin mimarileri bulunmaktadır. Bunlar genelde dönüş eksenlerinin konumuna göre yatay eksenli rüzgâr türbinleri (YERT) ve düșey eksenli rüzgâr türbinleri (DERT) olarak siniflandırılırlar. Modern 3 kanatlı YERT'ler geniş bir dönme hızı (veya boyutsuz haliyle uç hı oranı $\left.=\omega R / V_{\infty}\right)$ aralığında en verimli mimariye sahiptirler ve bu sebeple onlarca yıldır en yaygın kullanılan türdür. Bunun ana sebeplerinden biri bu tip türbinlerde kanatların dönüşleri boyunca rüzgara aynı şekilde maruz kalmaları sebebiyle görece daha yüksek güç üretme potansiyeline sahip olmalarıdır. Dolayısıyla YERT'lere yıllar içinde büyük yatırımlar yapılmıştır [1]. Bu türbinlere alternatif kaldırma kuvveti temelli DERT'ler (Darrieus türbinleri) ise en geç 1930'lu yıllardan bu yana bilinmelerine rağmen [2], rüzgârı her yönden karşılama kabiliyeti, jeneratörün türbin altına konabilmesi, yönü değişken ve türbülanslı akışın olduğu şehir ve kırsal bölgelerinde kullanım kolaylığı ve ucuzluk gibi özellikleri dolayısıyla yeniden ilgi görmeye başlamışlardır [36].

DERT'lere olan bu yeni yönelim sebebiyle yeni çalışmalarla performans artış ve özellikle küçük ölçekli güç üretiminde YERT'lerle rakabet potansiyelleri bulunmaktadır [1]. Darrieus tipi DERT'lerin performansını inceleyen 1970’li yılların Sandria raporları hariç tutulursa [7-9], konu son yıllara kadar etraflıca incelenmemiştir ve bu konudaki birçok yayın son yıllara aittir.

Tescione ve ark. [10], H-tipi bir Darrieus türbininin art-izini parçacık görüntülemeli hız ölçümü (PGHÖ/PIV) tekniğiyle detaylı inceleyerek bu konunun öncülerinden biri olmuştur. $\mathrm{Bu}$ çalışma, uç hız oranının $\left(\omega R / V_{\infty}\right) 4.5$,
Reynolds sayısının $\left(2 \rho \omega R^{2} / \mu\right)$ ise $1.7 \times 10^{5}$ olduğu tek bir çalışma noktası için gerçekleştirilmiştir. İncelenen türbinin katılık oranı $(\sigma) 0.11$, boy oranı $(h / D)$ 1'dir. Çalışmanın ana bulguları şunlardır: 1) türbin art-izinin asimetrik olması, 2) yüksek türbülans sayesinde yayılımın artmasıyla art-izinin YERT'lere kiyasla daha erken toparlanması ve 3) ters yönde dönen girdapların etkileşim içine girmesiyle üç çap arka mesafeden sonra tekil girdap yapılarının ve kanat artizlerinin ortadan kaybolması, sadece kenarlarda ters yönde dönen girdap yapılarının kalması.

Lam ve Peng [11], aynı problemi iki ve üç boyutlu hesaplamalı akışkanlar dinamiği (HAD) yardımıyla incelemişlerdir ve deneylerle HAD arasında uyum gözlemlemişlerdir. $\mathrm{Bu}$ sayede, ileriki çalışmaların HAD yardımıyla belli bir güven aralığı içerisinde yapılabilmesinin önü açılmıştır.

Li ve ark. [12], yaptıkları deneysel çalışmada, NACA 0021 kanat kullanan iki kanatlı H-tipi Darrieus türbininin güç ve art-izi karakteristiklerini, ilk defa uç hızı oranına bağlı olarak, incelemişlerdir. $\mathrm{Bu}$ çalışmada hem rüzgâr tüneli, hem de saha testleri gerçekleştirmişlerdir. Saha testlerinde Reynolds sayısı kontrollü şekilde ayarlanamasa da rüzgâr tünelinde $1.62 \times 10^{5}-3.12 \times 10^{5}$ Reynolds aralığında inceleme yapılmıştır. $\mathrm{Bu}$ çalışmanın bulguları, güç katsayısının sadece uç hız oranına bağlı olmayıp, Reynolds sayısıyla da $\left(2 \rho \omega R^{2} / \mu\right)$ arttığ yönündedir. Saha testlerinde ise güç katsayısı, Reynolds sayısı değișkenliği ve türbülans sebebiyle yayılım göstermektedir. Ayrıca türbülans sebebiyle, saha testlerinde art-izi, rüzgar tünel testlerine göre, daha çabuk kaybolmaktadır. Yine rüzgar tüneli testlerine kıyasla, güç katsayısı, optimum uç hız oranı için saha testlerinde daha düşüktür, ancak düşük ve yüksek uç hız oranlarında daha yüksektir. Bu da, rüzgar 
tüneli (veya HAD) ile saha farkını ortaya koymaktadır.

Bahsi geçen detaylı inceleme çalışmalarının yanı sıra DERT'ler için çeşitli başarım iyileştirme çalışmaları da gerçekleștirilmiştir. Bunlar, genellikle rotor dișına stator yahut muhafaza yerleştirilmesi ve böylece akışın istenen șekilde yönlendirilmesi șeklindedir [1315]. Ayrıca, art-izinin DERT'lerde daha çabuk azalması sebebiyle tarla diziliminde yeni firsatlar ortaya çıkmaktadır. Buna göre DERT'ler YERT'lere göre daha yakın yerleştirilebilir ve hatta etkileşim sayesinde tekli DERT'lere klyasla güç artışı gözlemlenebilir [16-17]. Bu konudaki çalıșmalar ülkemizde de yakından takip edilmektedir [18].

Bu çalışmada, H-tipi bir Darrieus rüzgar türbininin kanatlarının firar kenarı tarafına basamaklar açılmasının (Șekil 1), türbinin güç katsayısı ve art-izi üzerindeki etkisi incelenecektir. Üzerinde basamak olan kanatlar genelde KF (Kline-Fogleman) kanatları olarak bilinmektedir [19] ve izole kanatlar üzerinde yapılan çalışmalar, bu basamakların bazı durumlarda, girdaplar sayesinde oluşan türbülans artışı ve akıșın yeniden kanat yüzeyine yapışmasıyla, kaldırma/sürükleme kuvvet oranı artışı potansiyelleri barındırdıklarını göstermiştir [20-22]. Bu sebeple, bu kanatların, kaldırma kuvveti temelli Darrieus türbinlerinde kullanılmalarının bir takım performans iyileștirmesi getirmesi beklenebilir. Bu konudaki veri eksikliği, spekülasyonların varlığı ve araştırma yapılması ihtiyacı Bos [23] tarafından da belirtilmiştir. Yazarın bilgisi dahilinde, basamaklı kanatlar bir Darrieus türbininde ilk defa kullanılacaktır.

$\mathrm{Bu}$ çalışmada, Tescione ve ark. [10] tarafindan kullanılan türbin temel alınmıștır. Bu türbin, iki adet simetrik NACA 0018 kanada sahiptir ve diğer özelliklerine bu makalenin giriş kısmında değinilmiştir. Kanatlar basamak içerecek şekilde değiştirilmiştir (Şekil 1) ve elde edilen türbinin başarımı, değiştirilmemiş (basamaksız) kanada sahip türbin ile karşılaştırılmıştır. Bunun için, Lam ve Peng [11] tarafindan kullanılan HAD yöntemi temel alınmıștır, çünkü bu yöntem, Tescione ve ark. [10] tarafından elde edilen deney verisi ile halihazırda doğrulanmıştır. Aynı doğrulama ayrıca gerçekleștirilmiștir ve yine aynı sonuçlar elde edilmiştir [24].

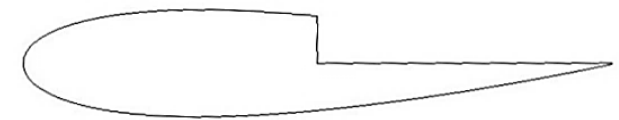

Şekil 1. Basamaklı NACA 0018 kanadı

\section{Materyal ve Metot}

Türbinin türbülanslı akıș alanını tahmin etmek için ANSYS Fluent $17^{\odot}$ sonlu hacim hesaplamalı akışkanlar dinamiği (HAD) yöntemi kullanılmıştır. Hesaplama alanı Şekil 2'de verilmiștir. Buna göre türbinin önünde, sağında ve solunda 5 çap mesafe, arkasında ise 11 çap mesafe bırakılmıştır.

Türbin kanatları, șekilde gösterildiği üzere, halka şeklinde bir bölge içinde dönmektedir. Bu çemberin içerisinde ve dışarısında durağan hesaplama ağı bulunmaktadır. Hesaplama ağı, toplamda 500 bin civarı üçgen ve dörtgen sonlu hacimden oluşmaktadır. Tıpkı doğrulanmış Lam ve Peng [11] çözümünde olduğu gibi, 60 bin civarı hacim Şekil 2'de tanımlanan halkanın içerisindeki iç bölgededir, 150bin hacim, kanatların olduğu halkadadır ve 280 bin hacim bu halkanın dışında kalan bölgededir. Kanatların olduğu halkadaki hesaplama ağı kaygan ağ (sliding mesh) yöntemi ile dönerek kanat hareketi istenen dönme hızı için modellenmektedir. 


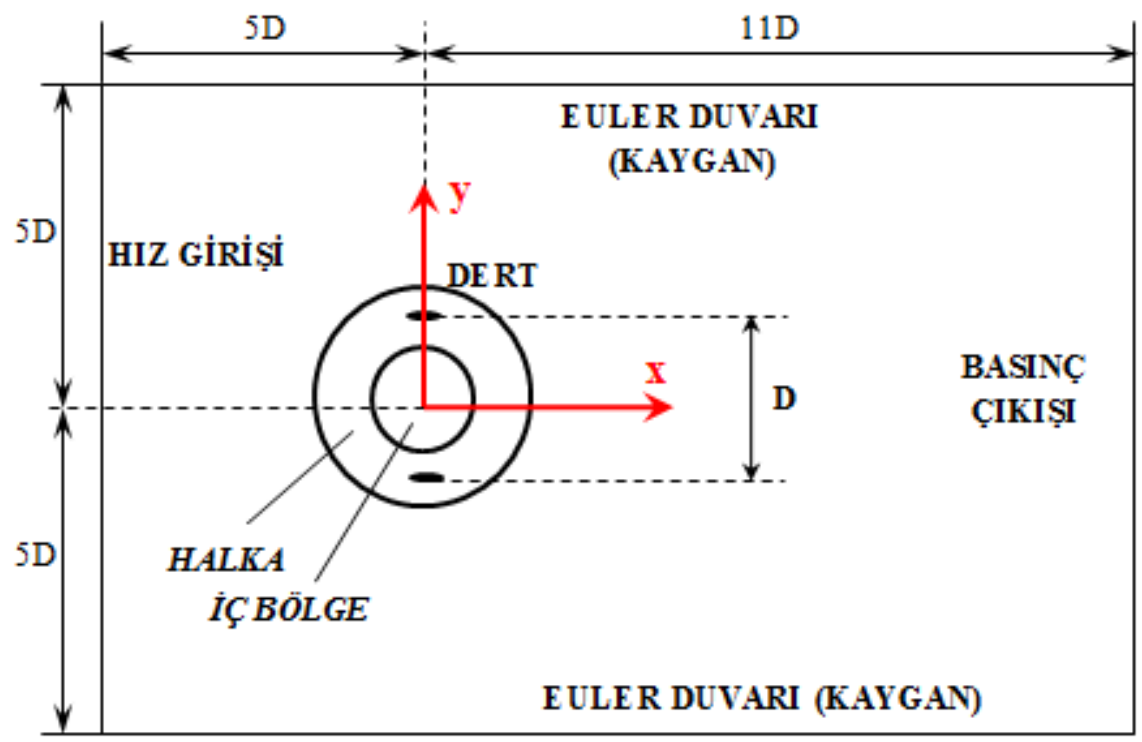

Şekil 2. Hesaplama bölgesi ve tanımlar

Türbülanslı sınır tabakayı çözmek için duvardan başlayarak 1.1 oranı ile büyüyen 20 dörtgen sinır tabakası elemanları kullanılmıştır. Duvara en yakın sınır tabaka elemanı, laminer alt bölgeyi (laminar sublayer) çözmektedir $\left(\mathrm{y}^{+}<3\right)$. Bu bölgenin modellenmesi (ilk sınır tabaka elemanının $\mathrm{y}^{+}>40$ olması durumu) yerine doğrudan çözülmesi, özellikle akış ayrılmalarının yoğun olduğu Darrieus türbinlerinde doğruluk için çok önemlidir. Hesaplama ağından bazı kritik kesitler Şekil 4 ve 5'te verilmiștir. $\mathrm{Bu}$ parametrelere sahip hesaplama ağından 3 adet yaratılmıştır. Birisi basamaksız durum için, diğerleri dıştan ve içten basamaklı durumlar içindir (Şekil 3).
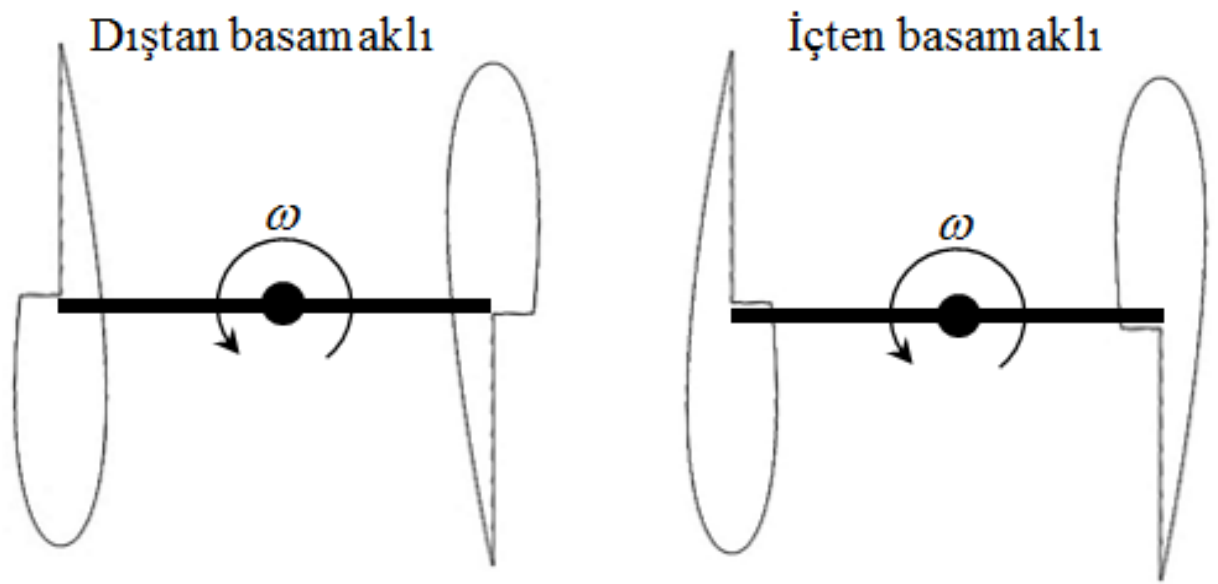

Şekil 3. İçten ve dıştan basamaklı tanımı 
S.Acarer / Kanatlarına Basamak Açmanın Darrieus Düşey Eksenli Rüzgar Türbini Güç Üretimine Etkisi

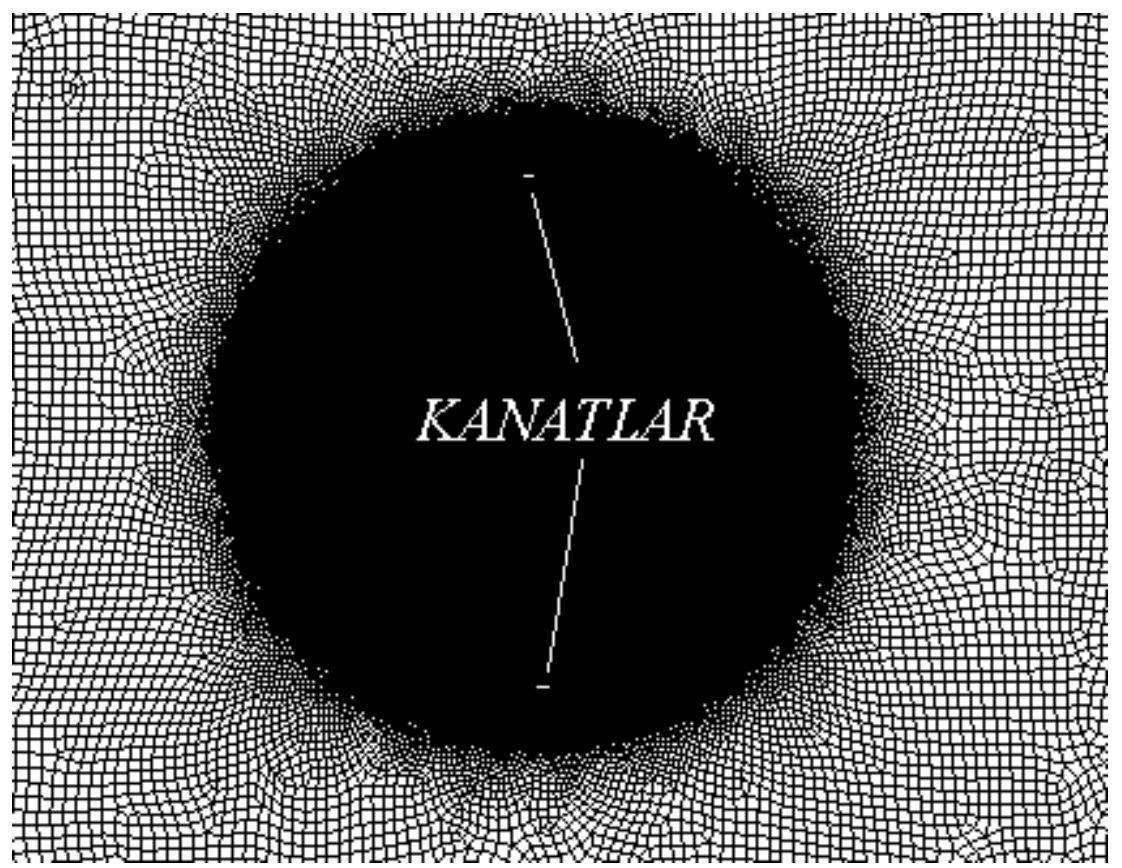

Şekil 4. Hesaplama ağı, uzaktan görünüş

Çözümde zamana bağlı Reynoldsortalanmış Navier-Stokes (Unsteady Reynolds-averaged Navier-StokesURANS) çözüm yöntemi kullanılmıştır. Süreklilik ve momentum bağlantısı için SIMPLEC șeması, hücre merkezi ve yüzeyi arası ara değeri bulmak için ikinci dereceden ve akış yönünü hesaba katan şema (second order upwind scheme) kullanılmıștır. Tüm bu yöntemlere, türbülansı çözmek için 4 denklemli "Transition SST" türbülans modeli eşlik etmektedir. Bu model, $\mathrm{k}-\mathrm{w}$ SST modelinin, 2 ek denklem vasıtasıyla laminer-türbülans geçiş modellemesi eklenmesiyle oluşmuştur ve Darrieus türbini hesaplamalarında deneyler ile uyumlu tahminler üretmiştir [11].

Zaman adımı, tıpkı doğrulanmış Lam ve Peng [11] çalışmasında olduğu gibi, bir turda 720 adım olacak şekilde seçilmiştir. Bir başka deyişle, bir zaman adımı 0.5 derecelik bir dönmeye karșılık gelmektedir. Bu da, yaklaşık 1 $10^{-4} \mathrm{sn}^{\prime}$ lik bir zamana karşılık gelmektedir.

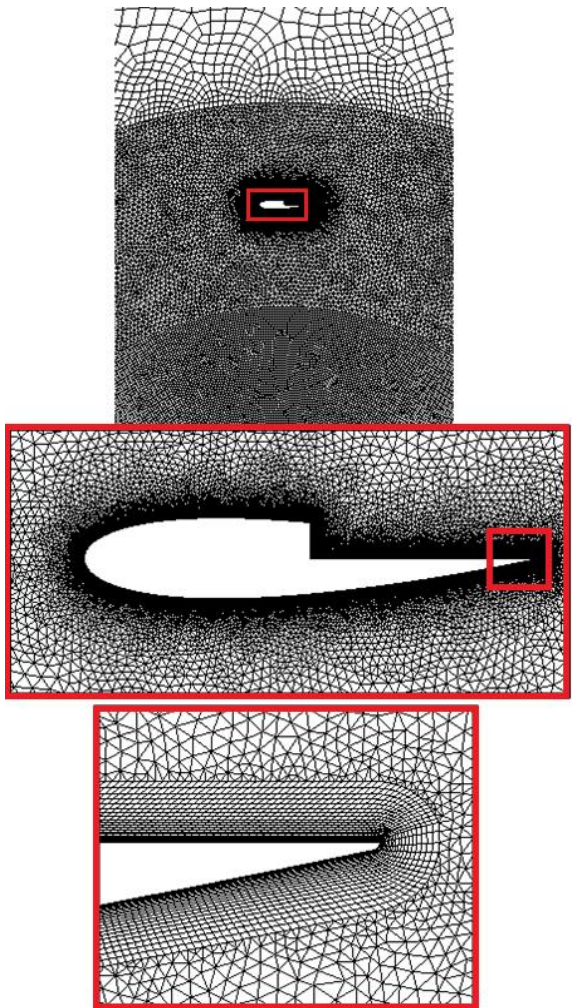

Şekil 5. Hesaplama ağı, yakından görünüşler 


\section{Bulgular}

Türbinlerin genel güç karakteristiğini gösteren boyutsuz dönme hızı olan uç hız oranı $\left(\omega R / V_{\infty}\right)$ ve güç katsayısı $\left(C_{p}=P /\left(0.5 \rho V_{\infty}{ }^{3} A\right)\right)$ grafiği Şekil $6^{\prime} \mathrm{da}$ sunulmuştur. Burada kanat üzerindeki ortalama Reynolds sayısı sabit tutulmuştur. Bu da, dönme hızı sabit tutularak rüzgâr hızının değiştirilmesiyle mümkün olmaktadır.

Şekilde açlkça görüldüğü üzere en yüksek gücün üretildiği uç hız oranında (4.5) en yüksek başarım, basamaksız (normal) kanatlara aittir. Kanatlara basamak eklenmesi gücü düşürmektedir. Bu uç hız oranında güç düşümü, dıştan basamak eklenmesi durumunda (Şekil 3) yaklaşık \%28, içten basamak eklenmesi durumunda ise yaklaşık \%44'tür. Ancak düşük uç hız oranında (1.5) tam tersi bir durum söz konusudur. Diștan basamaklı durumda, basamaksız duruma göre yaklaşık \%33 güç artışı gözlemlenmiştir. Bu sayede türbinin başlangıç momenti artmakta ve çalışma aralığı genişlemektedir.

Yüksek uç hız oranında güç düşüşünün sebebini bulmak için türbülans yoğunluğu Şekil 7'de gösterilmiştir. Burada açıkça görüleceği üzere basamaklı durumlarda türbülans yoğunluğu artmaktadır. Bunun ise artan sürüklenme (drag) ile türbin gücünü düşürdüğü tahmin edilmektedir. $\mathrm{Bu}$ duruma daha yakından bakmak için, üç durum için, türbin kanadının bir dönüşü boyunca oluşturduğu moment katsayıları (Moment $\left./\left(0.5 \rho V_{\infty}^{2} A_{\text {kanat }}\right)\right)$ Şekil 8'de sunulmuştur. Burada diştan basamaklı kanat ilk 180 derecelik dönüşte (rüzgârı karşılayan yönde) basamaksız kanada göre daha fazla moment üretse de son 180 derecede (türbinin arka bölgesinde) daha az moment üretmektedir. İçten basamaklı durumda ise tam tersi bir durum söz konusudur. Rüzgarı karşılayan yön olan ilk 180 derecelik yönde içten basamaklı kanatlar, basamaksız kanada göre daha az moment üretse de son 180 derecede daha fazla moment üretmektedir.

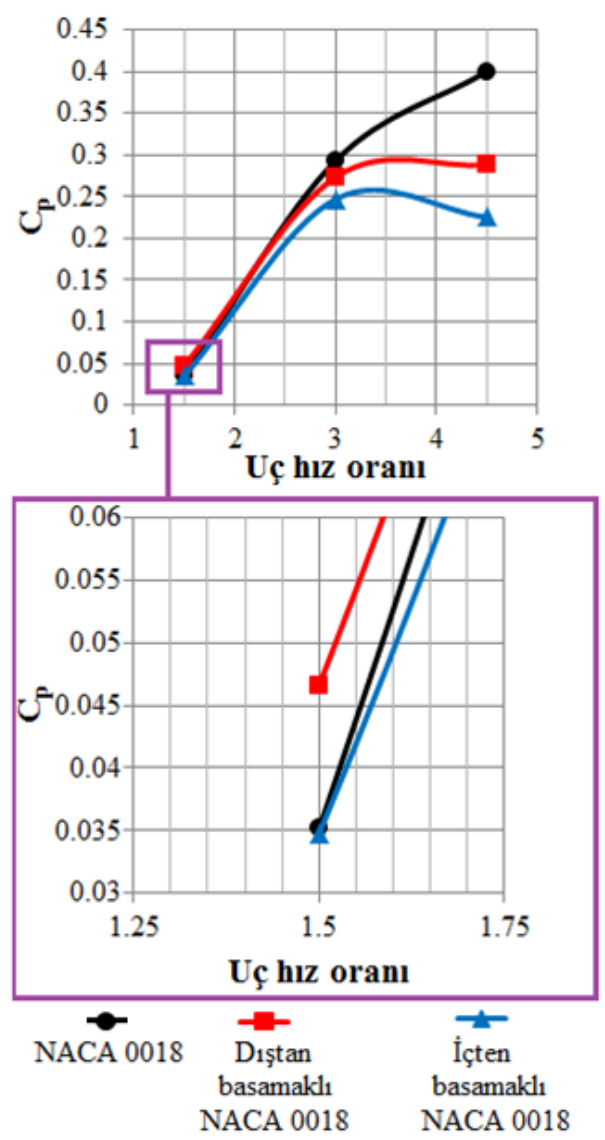

Şekil 6. Genel performans karşılaștırması

Şekil 9'da aynı yüksek uç hız oranında (4.5) her üç türbin tipi için art-izi kiyaslamaları sunulmuştur. Burada her bir zaman adımında veriler kaydedilmiştir, daha sonra tüm bu veriler yazılan bir bilgisayar programı yoluyla ortalanmıştır. Kısacası, sunulan art-izleri zamanda ortalanmış verileri göstermektedir. 

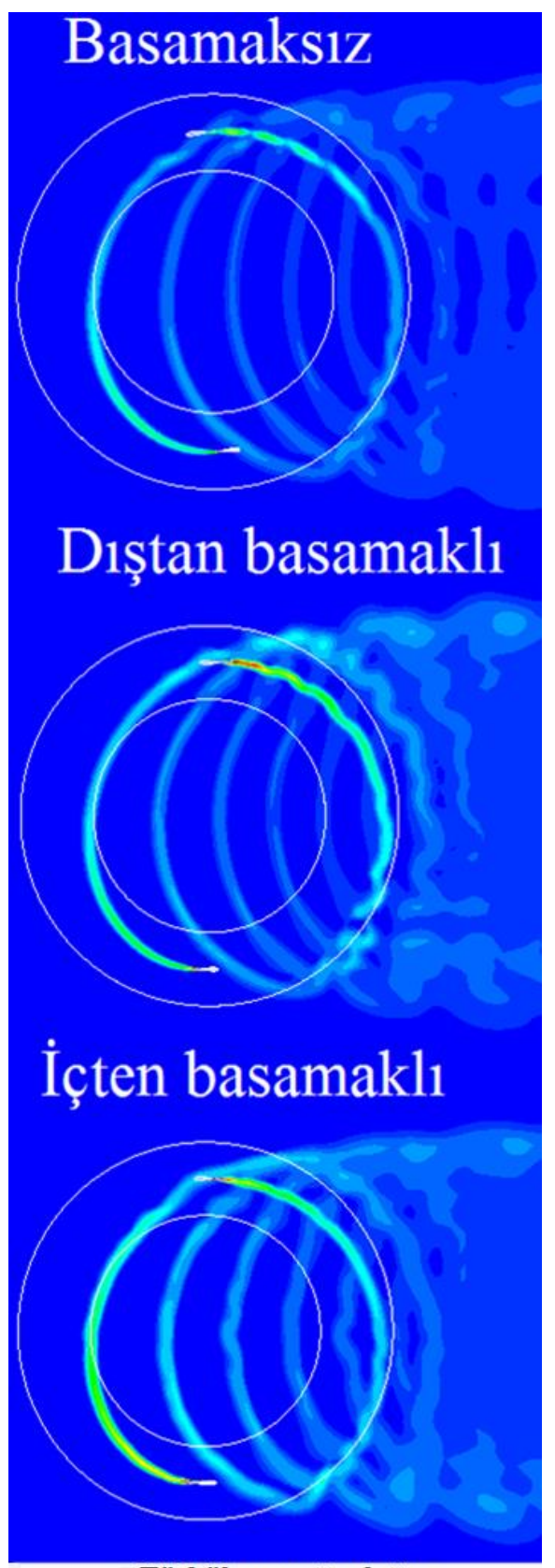

Türbülans yoğunluğu

0 10

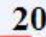

Şekil 7. Uç hız oranı 4.5 için türbülans yoğunluğu karşılaştırması

Șekil 9 incelendiğinde, basamaksız ve dıștan basamaklı türbinler benzer artizlerine sahiptirler. İçten basamaklı durumda ise hizlar genelde daha yüksektir. Buna sebep olarak içten basamaklı durumda rüzgardan az enerji soğurulması gösterilebilir. Bu sayede rüzgar hızları yüksek kalmaktadır. Diştan basamaklı durumda ise rüzgardan daha az enerji soğurulmasına rağmen türbülanstan kaynaklı basınç kayıpları vasıtasıyla basamaksız durumla benzer art-izi karakteristiği gözlemlenmiștir. $\mathrm{Bu}$ tahminler ve çlkarımlar haricinde art-izi hız karșılaștırmaları arasında anlamlı bir fark olmadığı sonucuna varılmıştır.

Düşük uç hız oranında (1.5), dıștan basamaklı kanatların, normal kanatlara göre daha yüksek güç üretmesinin sebebini bulmak için, tıpkı yüksek dönme hızlı durumda yapıldığı gibi, bir kanadın dönüş boyunca oluşturduğu moment katsayısı

(Moment $\left./\left(0.5 \rho V_{\infty}^{2} A_{\text {kanat }}\right)\right)$ Şekil 10 'da sunulmuştur. İçten basamaklı durum, güç artışı getirmediği için karşılaştırmaya dahil edilmemiştir ve sadece diștan basamaklı ve normal kanat arasındaki fark vurgulanmıștır. Burada ilk bakışta büyük farklar gözükmese de, diştan basamaklı durumda, normal kanatlı durumda gözlemlenen eksi moment dip noktalarının daha yumuşak oluştuğu görülmüştür. Bu da, yüksek hücum açısı değişikliklerinin oluştuğu düşük dönme hızlarında basamak eklemenin daha yumuşak bir perdövites (stall) karakteristiği yarattığını ortaya koymaktadır. İlk 60-70 derecede (kanadın üstte bulunduğu konum sıfır derece olmak üzere) büyük artı momentler üretilse de, sonraki açllarda üretilen eksi momentler bu kazanımı azaltmaktadır. Diştan basamaklı durumda daha az olan eksi moment dip değerlerinin ortalama moment ve gücü arttırdığı sonucuna varılmıștır. $\mathrm{Bu}$ artışın miktarı ise, yukarıda da bahsedildiği üzere $33 \%$ olarak tahmin edilmiştir. 
S.Acarer / Kanatlarına Basamak Açmanın Darrieus Düşey Eksenli Rüzgar Türbini Güç Üretimine Etkisi

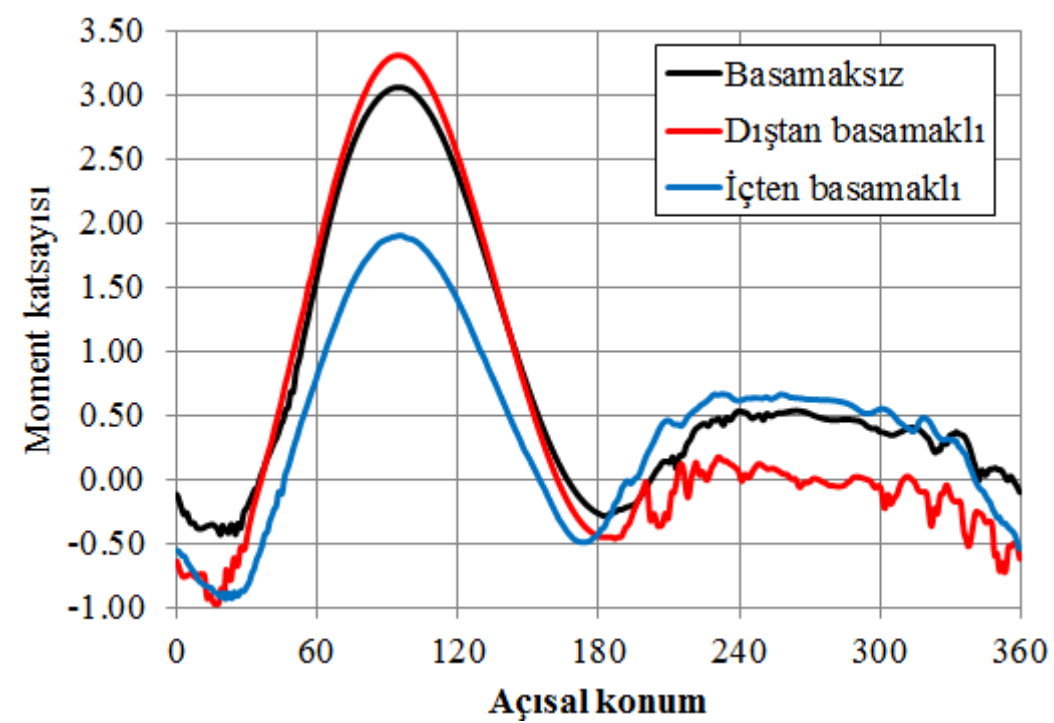

Şekil 8. Uç hız oranı 4.5 için tek kanadın çevresel yönde oluşturduğu moment katsayısı
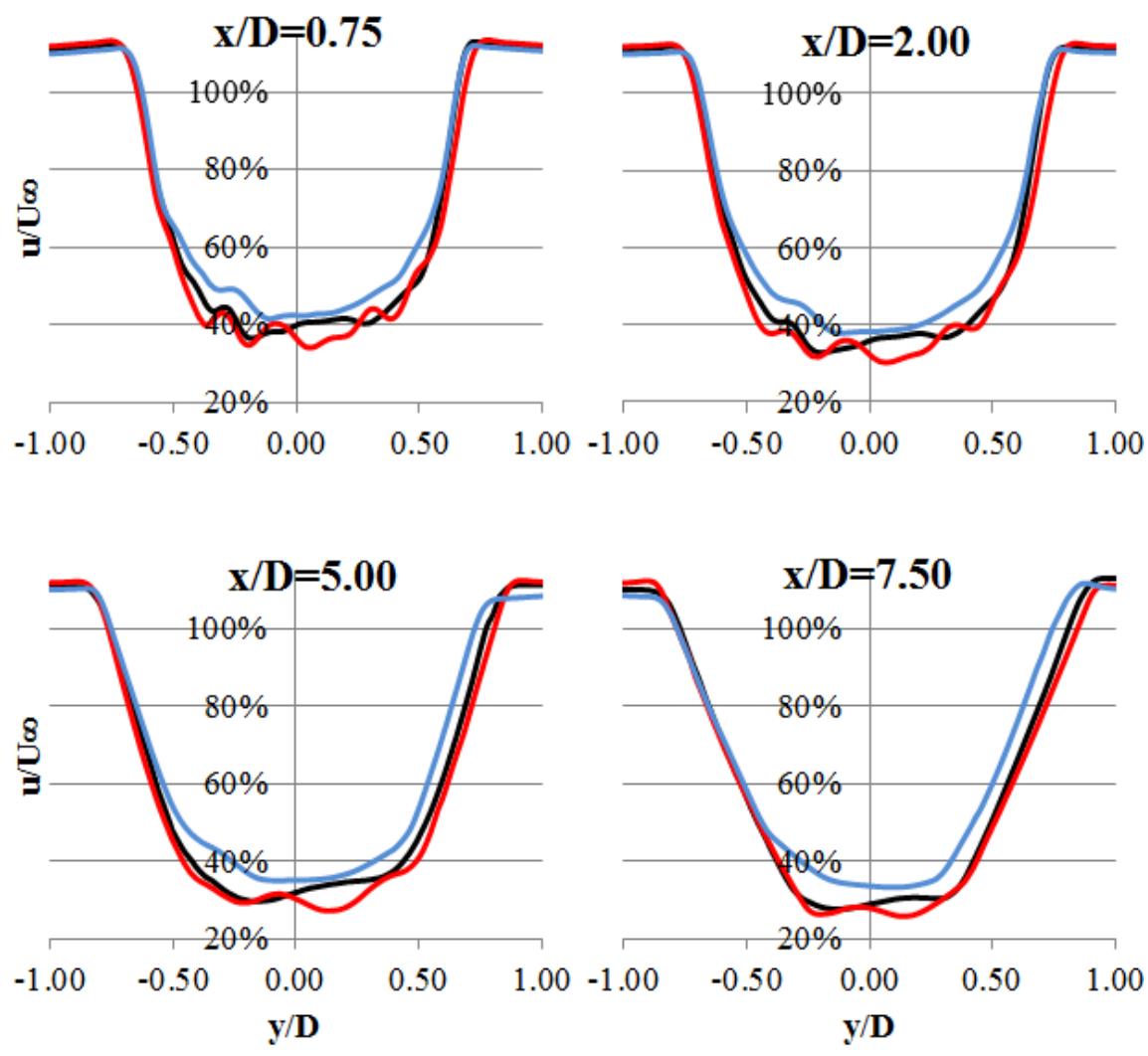

-Basamaksız —Diştan $\quad$ - Içten basamakl

Şekil 9. Uç hız oranı 4.5 için art-izi hız karşılaştırması 


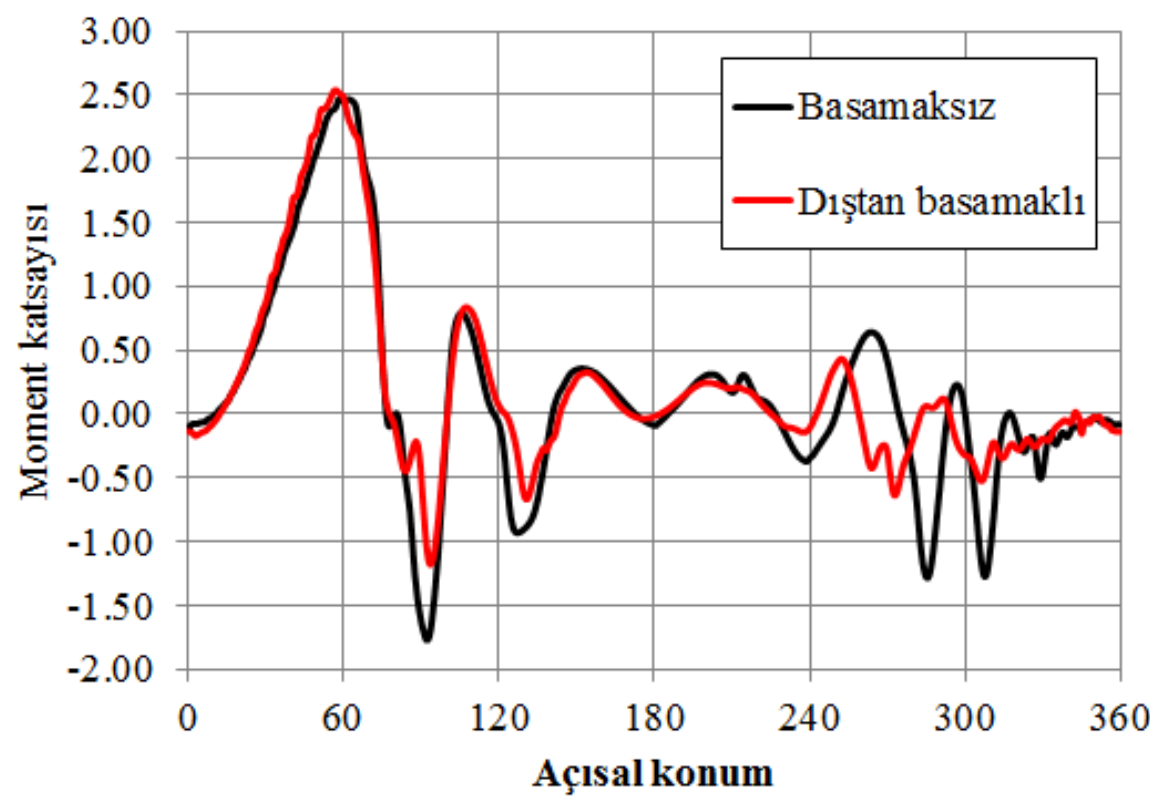

Şekil 10. Uç hız oranı 1.5 için tek kanadın çevresel yönde oluşturduğu moment katsayısı

\section{Tartışma ve Sonuç}

Bu çalışmada, bir kanadın firar tarafına basamak açmanın (Kline-Fogleman kanatları), literatürde belirtildiği üzere, o kanadın kaldırma/sürüklenme kuvvet oranını arttırma yönünde bir etkiye sahip olabileceği tezinden yola çıkılmıştır. Buna göre, kanada basamak açmanın, kaldırma kuvveti temelli bir türbin olan ve yoğunlukla çalışlan güncel bir bilimsel araştırma konusu olan Darrieus tipi düșey eksenli rüzgar türbinlerinde güç üretimi yönünden olumlu etkisinin olabileceği değerlendirilmiştir. Darrieus türbinlerinde gözlemlenen dinamik perdövites (stall) ve karmaşık akış özellikleri sebebiyle izole kanat verisiyle bir çlkarımda bulunmak, özellikle niceliksel veri gerektiğinde, zordur. Bu sebeple kanatlar doğrudan türbin üzerinde denenmiștir.

Gerçekleştirilen doğrulanmıș hesaplamalı akışkanlar dinamiği (HAD) analizleri sonucunda, kanada basamak açmanın yüksek uç hız oranlarında (dönme hızlarında), beklentinin aksine, elde edilen gücü \%28 (dıştan basamaklı) ile \%44 (içten basamaklı) arasında düșürdüğ̈̈ belirlenmiștir. Ancak, düşük uç hız oranlarında (dönme hızlarında), dıştan basamak açmanın, gücü ve momenti $33 \%$ oranında arttırdığı gözlemlenmiştir. $\mathrm{Bu} d \mathrm{da}$, türbinin dönmeye başlamasını kolaylaştırmaktadır ve çalışma aralığını genişletmektedir.

Yüksek uç hız oranında güç düşümünün sebebinin, türbin arkasında yaratılan yüksek türbülans ve sürüklenme kuvvetinin olduğu düşünülmektedir. Ancak olumlu bir şekilde, yine aynı yüksek uç hız oranında ve dıştan basamak açılan durumda, türbinin rüzgarı karşıladığı ön bölgede önemli bir güç artışı gözlemlenmiștir (maksimum değerde \%10 artış). Kısacası güç düşümü, verimsizliklerin olduğu arka kısımda ortaya çıkmıştır. Düşük uç hız oranlarında güç artışının ise daha yumuşak perdövites (stall) karakteristikleri sebebiyle çevresel yönde moment hareketliliğini yumuşatarak (dip değerleri 
yükselterek), ortalama momenti yükselttiği sonucuna varılmıştır.

Sonuç olarak yapılan çalışmalar, ileriki çalışmalarda çalışılabilecek olan optimize edilmiş basamak geometrilerinin (basit çentikler açma gibi) ve aktif akış kontrol yöntemlerinin, bahsi geçen olumsuzlukları ortadan kaldırarak, güç artış potansiyeli vadedebileceği gerçeğini ortaya koymaktadır.

\section{Teşekkür}

Başta Yrd. Doç. Dr. Ziya Haktan Karadeniz olmak üzere, Doç. Dr. Alparslan Turgut'a, Araş. Gör. Erinç Baytekin'e ve Mak. Yük. Müh. İskender Kökey'e Darrieus rüzgar türbinleri ve bu türbinlerin incelenmesi konusunda açtığı ufuklar sebebiyle teşekkür ederim. Araș. Gör. Erinç Baytekin'e ayrıca geometri oluşturma konusunda gösterdiği yardım için teşekkür ederim.

\section{Kaynakça}

[1] Paraschivoiu I. 2002. Wind Turbine Design: With Emphasis on Darrieus Concept. Polytechnic International Concept, Montreal, $450 \mathrm{~s}$.

[2] Darrieus G. 1931. Turbine Having Its Rotating Shaft Transverse to the Flow of the Current. U.S. Patent $1,835,01808$.

[3] Howell R, Qin N, Edwards J, Durrani, N. 2010. Wind Tunnel and Numerical Study of a Small Vertical-Axis Wind Turbine, Renewable Energy, Cilt 35, s. 412422.

DOI:10.1016/j.renene.2009.07.025

[4] Sutherland H J, Berg, D E, Ashwill T D. 2012. A Retrospective of VAWT Technology. Sandia Report SAND2012-0304.
[5] Balduzzi F, Bianchini A, Maleci R, Ferrara G. 2016. Critical Issues in the CFD Simulation of Darrieus Wind Turbines, Renewable Energy, Cilt 85, s. 419-435.

DOI: 0.1016/j.renene.2015.06.048

[6] Goude, A. 2012. Fluid Mechanics of Vertical Axis Turbines: Simulations and Model Development. Digital Comprehensive Summaries of Uppsala Dissertations from the Faculty of Science and Technology 998, Uppsala University.

[7] Banas J F, Sullivan W N. Sandia. 1976. Vertical-Axis Wind Turbine Program Technical Quarterly Report. Sandia Laboratuvarları.

[8] Worstell M H. 1978. Aerodynamic Performance of the 17 Meter Diameter Darrieus Wind Turbine. Sandia Laboratuvarları.

[9] Sheldalh R E, Klimas P C, Feltz L V. 1980. Aerodynamic Performance of a 5-Metre-Diameter Darrieus Turbine With Extruded Aluminum NACA-0015 Blades. Sandia Laboratuvarları.

[10] Tescione G, Ragni D, He C, Ferreira C J S, Bussel C J W. 2014. Near Wake Flow Analysis of a VerticalAxis Wind Turbine By Stereoscopic Particle Image Velocimetry. Renewable Energy, Cilt 70, s. 4761.

DOI:10.1016/j.renene.2014.02.042

[11] Lam H F, Peng H Y. 2016. Study of Wake Characteristics of a Vertical Axis Wind Turbine by Two and Three Dimensional Computational Fluid Dynamics Simulations, Renewable Energy, Cilt 90, s. 386398. DOI:10.1016/j.renene.2016.01.011

[12] Li Q, Maeda T, Kamada Y, Murata J, Yamamoto M, Ogasawara T, Shimizu K, Kogaki T. 2016. Study on Power Performance for 
Straight-Bladed Vertical Axis Wind Turbine by Field and Wind Tunnel Tests. Renewable Energy, Cilt 90, s. 291-300.

DOI:10.1016/j.renene.2016.01.002

[13] Khosrowponah, S. 1984. Experimental Study of the CrossFlow Turbine: Colorado State University, Doktora Tezi.

[14] Colley G, Mishra R, Rao H V, Woolhead R. 2010. Effect of Rotor Blade Position on Vertical Axis Wind Turbine Performance. International Conference on Renewable Energy and Power Quality (ICREPQ 10), Granada, İspanya.

[15] Fukutomi J, Shigemitsu T, Daito H. 2011. Study on Performance and Flow Condition of a Cross-Flow Wind Turbine With a Symmetrical Casing, Journal of Fluids Engineering, Cilt 133, s. 490-501. DOI:10.1115/1.4004023

[16] Araya D B, Craing A E, Kinzel M, Dabiri J. 2014. Low order Modeling of Wind Farm Aerodynamics Using Leaky Rankine Bodies, Journal of Renewable and Sustainable Energy, Cilt 6.

DOI: $10.1063 / 1.4905127$

[17] Dabiri J, Greer J R, Koseff J R, Moin P, Peng J. 2015. A New Approach to Wind Energy: Opportunities and Challenges, AIP Conference Proceedings 1652 (51), Berkeley, ABD.

[18] Karadeniz, Z.H. 2015. Düşey Eksenli Rüzgar Türbini Araştırmalarında Son Gelişmeler. 8. Yenilenebilir Enerji Kaynakları Sempozyumu, Adana, Türkiye.

[19] Kline R. 1985. The Ultimate Paper Airplane. Simon and Schuster Publication, New York.
[20] Fertis D G. 1994. New Airfoil Design Concept with Improved Aerodynamic Characteristics, Journal of Aerospace Engineering, Cilt 7, s. 328-339. DOI:10.1061/(ASCE)08931321(1994)7:3(328)

[21] Witherspoon S, Finaish F. 1996. Experimental and Computational Studies of Flow Developments Around an Airfoil With Backward Facing Steps. AIAA-96-2481-CP.

[22] Karunakaran C S. 2013. Study of Flow Field over Fabricated Airfoil Models of NACA 23015 with Its Kline-Fogleman Variant, Advances in Aerospace Science and Applications, s. 95-100.

[23] Bos R. 2012. Self-Starting of a Small Urban Darrieus Rotor: Strategies to Boost Performance in LowReynolds-Number Flows. Delft University of Technology, Yüksek Lisans Tezi.

[24] Baytekin, E., Acarer, S., Karadeniz, Z.H., Turgut, A. 2016. Darrieus Tipi Bir Rüzgar Türbininde Kanat Ucu Hızı Oranının Art İzine Etkisi, 10. Uluslararası Temiz Enerji Sempozyumu (UTES), İstanbul, Türkiye. 